J. Clin. Chem. Clin. Biochem.

Vol. 27, 1989, pp. $601-604$

(C) 1989 Walter de Gruyter \& Co. Berlin - New York

\title{
Immunonephelometric Determination of the Apolipoprotein A-II
}

\author{
By G. Hafner, C. Luley, and W. Prellwitz \\ Institut für Klinische Chemie und Laboratoriumsmedizin der Johannes Gutenberg-Universität Mainz, FRG
}

(Received January 6/May 29, 1989)

Summary: A fully mechanized immunonephelometric method is described for the rapid and specific determination of apolipoprotein A-II in serum. The method utilizes commercially available sheep antiserum against human apolipoprotein A-II. Nephelometry was performed with the Behring Nephelometer Analyzer (BNA). A single determination can be performed in 12 minutes, requiring $10 \mu \mathrm{l}$ sample volume. The measuring range is about 0.08 to $1.25 \mathrm{~g} / 1$ apolipoprotein A-II. Precision is characterized by intra-assay coefficients of variation of $3.37 \%, 3.93 \%$ and $4.49 \%$ for apolipoprotein A-II concentrations of $1.22 \mathrm{~g} / \mathrm{l}, 0.376 \mathrm{~g} / \mathrm{l}$ and $0.185 \mathrm{~g} / \mathrm{l}$, and inter-assay coefficients of variation of $4.27 \%$ for an apolipoprotein A-II concentration of $0.404 \mathrm{~g} / \mathrm{l}$, respectively. Accuracy of the method is shown by the close correlation of results with those from radial immunodiffusion $(\mathrm{r}=0.913, \mathrm{y}=1.091 \mathrm{x}-0.033, \mathrm{n}=75)$.

\section{Introduction}

HDL-lipoproteins are very important plasma lipoproteins, which provide protection against premature arteriosclerosis. Furthermore, the HDL concentration and the apolipoprotein profile are useful diagnostic aids in certain illnesses (1). This not only applies to the rare Tangier disease (2), but also to cholestasis (3) and the different forms of myeloma (4). The concentration of apolipoprotein A-II sẽems to be specifically helpful as an indicator of alcohol abuse (5), and in the diagnosis of cirrhosis and neoplasms of the liver (6).

Numerous methods for measuring apolipoprotein AI have been described which can be used by both research and routine laboratories. In contrast, there are relatively few methods for apolipoprotein A-II (the second most common HDL protein), which permit the determination of a reasonably large number of samples automatically and with a large measuring range. This paper describes the use of a fully automatic nephelometer combined with commercially available sheep antiserum which satisfies these requirements.

\section{Materials and Methods}

The antiserum used is a commercially available sheep antiserum against human apolipoprotein A-II (Boehringer, Mannheim, FRG). When the monospecificity of this antiserum was examined by the immunoprecipitation of focussed HDL-apolipoproteins (7), only a single precipitation line, i.e. the familiar apolipoprotein A-II band, was formed. The following parameters were used for the operation of the Behring Nephelometer Analyzer (BNA; Behring, Marburg, FRG):

$\begin{array}{ll}\text { sample volume: } & 10 \mu \mathrm{l} \\ \text { sample dilution: } & 1: 20 \\ \text { antiserum volume: } & 20 \mu \mathrm{l} \\ \text { reagent 2-volume: } & 10 \mu \mathrm{l} \\ \quad \text { (N-additional reagent/ } & \\ \quad \text { precipitation) } & \\ \text { reaction buffer volume: } & 2 \times 100 \mu \mathrm{l} \\ \text { measuring time: } & 12 \mathrm{~min} \text { (fixed time) }\end{array}$

A commercial standard (Immuno, Heidelberg, FRG) was used to calibrate the nephelometer. Precision control was carried out with the $\mathrm{N}$-apolipoprotein standard serum (Behring, Marburg, FRG). As buffer system the N-reaction buffer (Behring, Marburg, FRG) was used. To suppress any non-specific secondary reactions, the $\mathrm{N}$-additional reagent/precipitation (Behring, Marburg, FRG) was used. All sample dilutions were accomplished with the N-diluent (Behring, Marburg, FRG). Lipaemic samples were pre-treated according to the manufacturer's instructions with lipoclean (Behring, Marburg, FRG).

Apolipoprotein A-II determination with radial immunodiffusion (RID) was carried out according to the manufacturer's 
instructions (Immuno, Heidelberg, FRG). The RID Reference Standard Apoproteins human (Immuno, Heidelberg, FRG) were used to compile the calibration curve.

The sample material used was serum without further preliminary treatment.

\section{Results}

The commercially available, monospecific antiserum is suitable for antigen determining tests with immunochemical methods, but it is not specially prepared for nephelometry. The precipitation is shown in figure 1. The curve obtained with the fixed-time-method shows that, in the case of this measuring method, the terminal point of the reaction has still not been reached after a period of 30 minutes. However, in the present method, the terminal point does not have to be reached, and measurements can be made towards

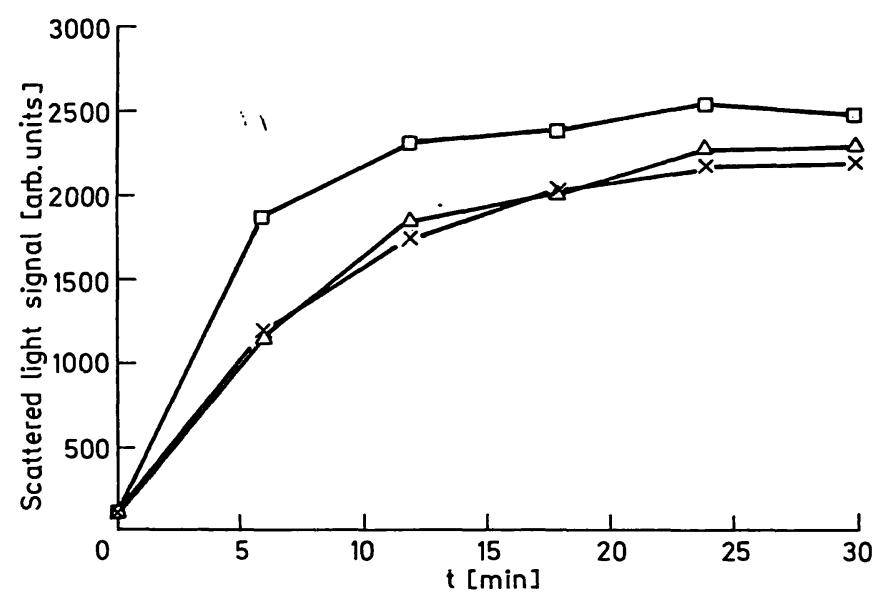

Fig. 1. Greatest diffused light signal produced during calibration of five different measuring times with minimum dilution of the standard for apolipoprotein A-II $(1: 5)$ (Calibration $1 \Delta$, Calibration $2 x$ ) and apolipoprotein A-I (1:5) ( $\square)$

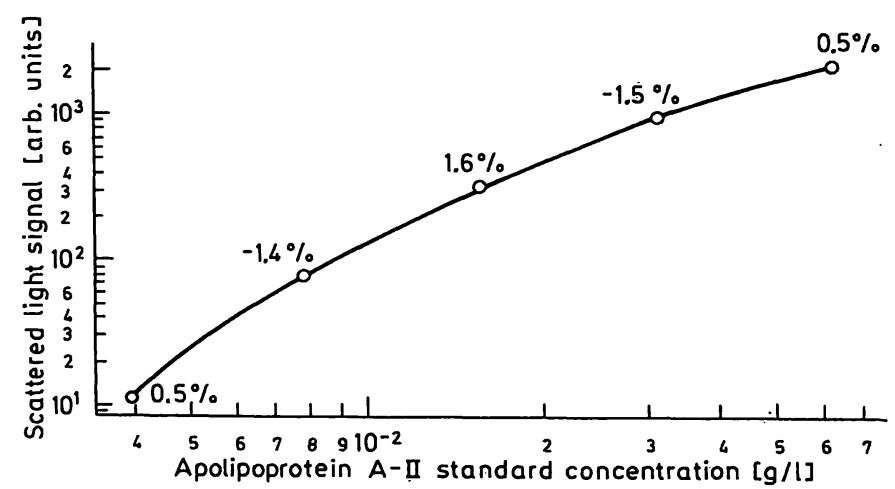

Fig. 2. Calibration curve of the apolipoprotein A-II with the Behring Nephelometer Analyzer. The apolipoprotein AII concentrations of the standard dilutions (geometric dilution series from $1: 5$ to $1: 80$ of a standard concentration of $0.312 \mathrm{~g} / \mathrm{l}$ ) and the intensity of the scattered light signal are shown. The figures given in $\%$ are the deviations from the curve calculated by the Behring Nephelometer Analyzer. the end of the reaction (about 80-90 percent of maximum precipitation should be achieved). This antiserum can therefore be used with this instrument for the nephelometric determination of the apolipoprotein A-II with a measuring time of 12 minutes. For comparison, the illustration shows the precipitation time curve of an antiserum specified for the nephelometric determination of 'ápolipoprotein A-I (Behring, Marburg, FRG).

A representative calibration curve in figure 2 shows the measuring signal which is dependent on the antigen concentration. Here, the measuring range is between $0.08 \mathrm{~g} / 1$ and $1.25 \mathrm{~g} / \mathrm{l}$ with a sample dilution of $1: 20$.

In an attempt to reduce costs by decreasing the amount of antiserum to $15 \mu \mathrm{l}$ or even $10 \mu \mathrm{l}$, the resulting turbidity was no longer sufficient to produce a utilizable measuring signal for the lowest measuring point. Evidently this is due to formation of soluble antigen-antibody complexes at low antigen concentration. This would mean that the measuring scale would only range from $0.16 \mathrm{~g} / 1$ to $1.25 \mathrm{~g} / \mathrm{l}$. Since measurement values around $0.2 \mathrm{~g} / 1$ are not uncommon, an antiserum quantity of $20 \mu \mathrm{l}$ was selected to give greater accuracy in this range.

At the recommended sample dilution, the measuring range embraces the normal range and the pathologically low range down to about $0.08 \mathrm{~g} / \mathrm{l}$. The linear course followed by the curves over the whole of the measuring range in figure 3 shows that the dilution or the automatic post-dilution of the samples by the instrument do not produce distorted values.

The precision of the method was verified by determining the within-series imprecision, and betweenseries imprecision. The results of the assays carried out with various pool serums are given in table 1.

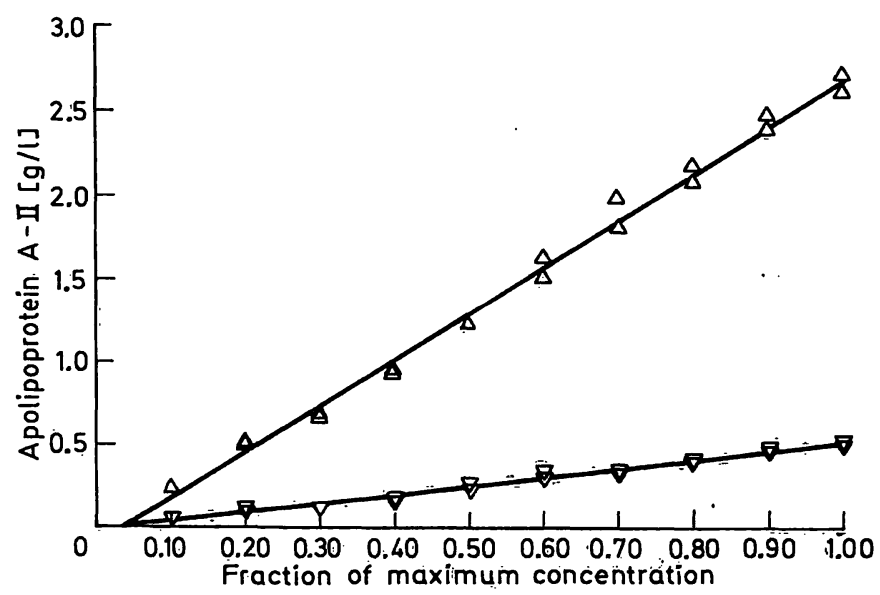

Fig. 3. Apolipoprotein A-II on the Behring Nephelometer Analyzer. Linearities in a low $(\nabla)(y=0.006 x-0.015)$ and in a high range $(\Delta)(y=0.028 x-0.09)$ 
Tab. 1. Precision of the immunonephelometric apolipoprotein A-II determination

\begin{tabular}{llll}
\hline & $\begin{array}{l}\text { Apolipoprotein } \\
\text { A-II concen- } \\
\text { tration }[\mathrm{g} / \mathrm{l}]\end{array}$ & $\begin{array}{l}\text { Impre- } \\
\text { cision } \\
{[\mathrm{CV}, \%]}\end{array}$ & $\begin{array}{l}\text { Number } \\
\text { of } \\
\text { samples }\end{array}$ \\
\hline Within series & 0.185 & 4.49 & 20 \\
& 0.376 & 3.93 & 20 \\
Between series & 1.122 & 3.37 & 20 \\
\hline
\end{tabular}

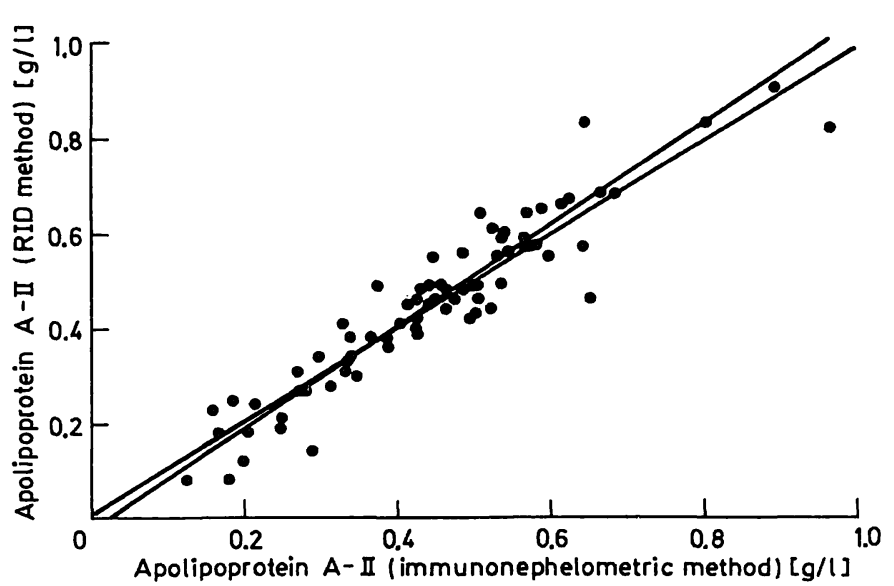

Fig. 4. Method comparison for apolipoprotein A-II determination in patient samples by the Behring Nephelometer Analyzer (abscissa) and by RID (ordinate): The linear regression function is $\mathrm{y}=1.091 \mathrm{x}-0.003$; the coefficient of correlation is $r=0.913$; the number of samples are $\mathrm{n}=75$

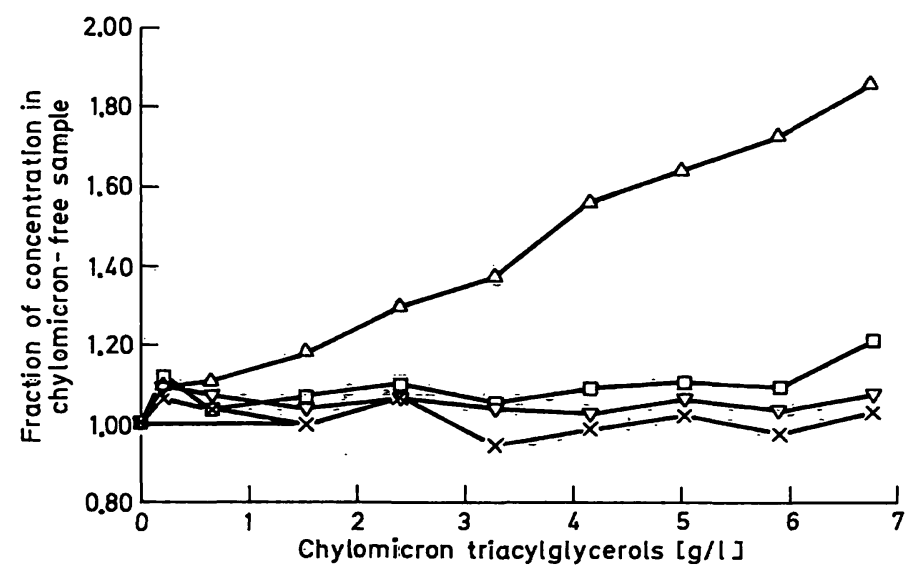

Fig. 5. Influence of chylomicrons on turbidity measurement. The graph shows the deviation of values for apolipoprotein A-II $(x)$ and IgA $(\nabla)$ after preliminary treatment with lipoclean, and apolipoprotein A-II ( Q) and IgA $(\Delta)$ without lipoclean treatment, from the values for chylomicron-free samples with increasing addition of triacylglycerol-bearing serum.

The high level of accuracy achieved in all concentration ranges permits each analysis to be carried out as a single determination. The accuracy of the method was checked by comparison with radial immunodiffusion. Comparison of the results (fig. 4) shows close agreement of the methods, $\mathrm{r}=0.913$ (Bablok \& Passing).

The influence of lipaemic samples on the nephelometric determination of apolipoprotein A-II, before and after treatment with lipoclean is shown in figure 5. Increasing quantities of chylomicrons (triacylglycerol values up to $7 \mathrm{~g} / \mathrm{l}$ ) were added to the serum. Haemolytic, icteric and heparinized samples displayed no influence on the apolipoprotein A-II assays. Samples can be frozen for months or kept cool at $4{ }^{\circ} \mathrm{C}$ to $8^{\circ} \mathrm{C}$ for a week until the determination is carried out.

\section{Discussion}

Despite the fact that the apolipoproteins of HDL are present in structural complexes with lipids, they can be determined quantitatively by conventional immunological techniques without further processing $(8,9)$. Although the antigenic determinants of apolipoprotein A-II in particular are masked by the protein-lipid bond inside the HDL (10), delipidation with organic solvents is not necessary (11). Haemolytic, icteric and heparinized samples do not interfere in nephelometric determinations. Only strongly lipaemic sera with a large proportion of chylomicrons can lead to nonspecific turbidity. In this case preliminary treatment and chylomicron-free transfer of the samples into the sample vessels of the nephelometer are neccessary. If the test is performed with a highly diluted sample $(1: 20)$, and additional reaction/precipitation, which suppresses non-specific turbidity, preliminary treatment with lipoclean is not neccessary up to triacylglycerol values of $7 \mathrm{~g} / \mathrm{l}$ ).

Apart from a commercially available standard, the method described also uses a commercially available, monospecific antiserum and can be carried out with a nephelometer of the type used for clinical chemical work in routine laboratories. Since no more than 20 $\mu \mathrm{l}$ of antiserum is required for the test, the costs remain at a reasonable level. In addition to the high level of automation, this measuring method also has a very wide measuring range from about $0.1 \mathrm{~g} / \mathrm{l}$ to over $2.5 \mathrm{~g} / \mathrm{l}$. Thus it is clearly superior to immunoturbidimetry, which has a working range of $0.25-$ $0.99 \mathrm{~g} / \mathrm{l}(8), 0.207-0.83 \mathrm{~g} / \mathrm{l}(9)$ or $0.075-0.3 \mathrm{~g} / \mathrm{l}(11)$. Likewise the effective measuring range of $0.14-1.14$ $\mathrm{g} / \mathrm{l}$, which can be achieved with an enzyme-linked immunoabsorbent assay (12), is smaller. The high level of precision expected with automated methods is easily achieved (tab. 1). Comparison with the RID values also shows good agreement $(r=0.913)$. The immunoturbidimetric methods require measuring times of 12.5 minutes (9), 25 minutes (11) and 60 
minutes (8), which facilitate a high sample throughput. With a measuring time of 12 minutes, the nephelometric method described is thus one of the quickest determination procedures for apolipoprotein A-II.

In summary, a routine procedure for apolipoprotein A-II has been established, using the Behring Nephelometer Analyzer, combined with a commercial anti- serum and a commercial standard and controls. The advantages, compared with other methods, are the high sample throughput and its very wide measuring range.

\section{Acknowledgement}

if

We thank $D$. Jöckel for her expert technical așsistance.

\section{References}

1. Alaupovic, P. (1983) Determination of plasma apolipoprotein profiles in patients with dyslipoproteinemias. Biologie Prospective 5e Colloque International de Pont-à-Mousson, Masson éd. pp. 683-689.

2. Schaefer, E. J., Kay, I. L., Zech, L. A. \& Brewer, H. B. (1982) Tangier Disease High density lipoprotein deficiency due to defective metabolism of an abnormal apolipoprotein A-I (apo A-I Tangier). J. Clin. Invest. 70, 934-945.

3. Cordova, C., Musca, A. \& Luliano, L. (1984) Apolipoproteins A-I, A-II and B in chronic active hepatitis and in liver cirrhotic patients. Clin. Chim. Acta 137, 61-66.

4. Hachem, H, , Favre, G., Raynal, G. \& Soula, G. (1983) Lipoproteins plasmatiques et myelome multiple. Variations des constituants lipidiques des HDL et des apolipoproteines A-I et B. Ann. Biol. Clin. 41, 181-185.

5. Puchois, P. (1982) Evaluation des lipoproteines et des apolipoproteines chez les sujets cirrhotiques et les buveurs excessifs. These 3eme Cycle, Faculte de Pharmacie, Lille, France.

6. Heuck, C. C. H., Erbe, I. \& Flint-Hansen, P. (1983) Immunonephelometric determination of Apo A-I in hyperlipoproteinemic serum. Clin. Chem. 29, 120-125.
7. Luley, C., Prellwitz, W., Oster, O. \& Kloer, H. U. (1987) Determination of Apolipoprotein Variants by Isoelectric Focusing in Agarose. Anal. Biochem. 163, 182-187.

8. Schriewer, H., Emke, F. \& Assmann, G. (1985) Turbidimetric Assay of Apolipoprotein A-III. J. Clin. Chem. Clin. Biochem. 23, 355-359.

9. Hachem, H., Raynal, G., Hamza, M., Canal, P. \& Soula, G. (1985) Automated Immunoturbidimetric Assay of Serum Apolipoprotein A-II Using the Cobas-Bio Centrifugal Analyser: Influence of Hyperlipoproteinemia. Clin. Biochem. 18, 332-337.

10. Musliner, T., Garner, P. A., Henderson, L. O. \& Herbert, P. N. (1982) Radioimmunoassay of apolipoprotein A-II. Arteriosclerosis 2, $160=169$.

11. Rifai, N. \& King, M. E. (1986) Immunoturbidimetric Assays of Apolipoproteins A, AI, AII, and B in Serum. Clin. Chem. 32, 957-961.

12. Stein, E. A., DiPersio, L., Pesce, A. J., Kashyap, M., Kao, J., Srivastava, L. \& McNerney, C. (1986) Enzyme-Linked Immunoabsorbent Assay of Apolipoprotein AII in Plasma, with Use of a Monoclonal Antibody. Clin. Chem. 32, 967971.
Dr. Gerd Hafner

Institut für Klinische Chemie und Laboratoriumsmedizin Johannes Gutenberg-Universität Langenbeckstraße 1

D-6500 Mainz 